\title{
BILATERAL CLEIDOHYOIDEUS ACCESSORIUS MUSCLE-A CASE REPORT
}

Naveen Kumar Bandarupalli, Srinivasa Rao Bolla

1. Assistant Professor, Department of Anatomy, Mamatha Medical College, Khammam, Andhra Pradesh.

2. Assistant Professor, Department of Anatomy, Mamatha Medical College, Khammam, Andhra Pradesh.

\section{CORRESPONDING AUTHOR}

Srinivasa Rao Bolla, Assistant Professor, Department of Anatomy, Mamata Medical College, Khammam- 507001.

E-mail: bolla.srinivas@gmail.com Ph: 00919440047894

ABSTRACT: Accessory muscles are rare anatomical variants which may have clinical implications. Variations of the muscles in the infrahyoid region assume clinical significance during diagnostic procedures and surgical operations in the region of neck. An unusual muscle "Cleidohyoideus accessorius" was found in the infra hyoid region bilaterally during routine dissection of neck region in an adult male cadaver. On both the sides muscle had its origin from the superior surface of the middle one third of the clavicle. The muscle coursing upward, lateral to the sternohyoid, was inserted into the hyoid bone. The other infra hyoid muscles including omohyoid were intact and in their typical form. The accessory muscle received its nerve supply from ansa cervicalis. Here we report a variation of rare occurrence, a case of bilateral accessory muscle "Cleidohyoideus accessorius", its embryological and clinical considerations are being reviewed here.

KEY WORDS: Accessory muscle, infrahyoid, Cleidohyoideus accessorius, Anatomic variation

INTRODUCTION: There are many reports of variations of the neck muscles. It has been noted from the review of literature that the omohyoid muscle is most frequently showing variations. A variant of omohyoid presenting as an additional muscle belly extending between clavicle and hyoid bone ${ }^{1}$, The superior belly of omohyoid attached to the transverse process of the C6 anterior to the scalenus medius ${ }^{2}$, double omohyoids ${ }^{3,4}$, absence of superior belly ${ }^{5}$, short omohyoid ${ }^{4}$ and cleidohyoid ${ }^{4,6}$ were reported.

From the different types of variations in the infrahyoid muscles, the muscles extending between clavicle and hyoid bone were classified as cleidohyoid muscles by Loth as early as $1912^{7}$. A step ahead by Steinbach who in 1923 , bestowed a status of an accessory muscle to it naming it as Cleidohyoideus accessorius, defining it as a muscle attached to the clavicle and hyoid bone when omohyoid was also present in its typical form $^{8}$. It has also been reported amongst many variations of omohyoid, documented by Bergman and his associates in their Compendium of human anatomical variations ${ }^{9}$. Most of the reports have not specified the laterality of the accessory muscle. Others have reported the unilateral occurrence ${ }^{10}$ and bilateral "Cleidohyoideus accessorius" 11.

Here we present a variation of rare occurrence, a case of bilateral accessory muscle "Cleidohyoideus accessories" its embryological and clinical considerations are being reviewed here.

CASE REPORT: During routine dissection of neck region for our medical undergraduate gross anatomy course, one adult south Indian male cadaver of 62 years old donated to the 
department of Anatomy, showed presence of an unusual muscle "Cleidohyoideus accessorius" in the infrahyoid region on both the sides. Muscles on both the sides were attached to the superior surface of the middle third of clavicle behind the clavicular portion of the sternocleidomastoid muscle and extending upward lateral to the Sternohyoid, got inserted into the hyoid bone [Fig.1]. Right muscle measured $12.3 \mathrm{cms}$ long, $4.0 \mathrm{cms}$ wide at the clavicle and $1.5 \mathrm{cms}$ at the hyoid bone. Muscle on the left side was $11.0 \mathrm{c} \mathrm{ms}$ long and $3.0 \mathrm{cms}$ wide a t clavicle and $0.8 \mathrm{cms}$ at the hyoid bone. On both the sides the muscle was supplied by a branch from ansa cervicalis. There was an intact well developed Omohyoid muscle in its typical form as seen normally in most of the cases. Sternohyoid and Sternothyroid were well developed and were seen in their usual forms.

DISCUSSION: The incidence of omohyoid anomalies among infra hyoid muscles is high. Omohyoid differs from the other three infrahyoid muscles (sternohyoid, sternothyroid, and thyrohyoid) in its course. This is due to the formation process of the infrahyoid muscles ${ }^{12}$. Anderson has theorized that the origin of the superior belly of the omohyoid muscle differs from that of the inferior belly ${ }^{13}$.

The infrahyoid muscles are formed from a muscle primordium occurring in the anterior cervical area ${ }^{14}$. The muscle primordium is first divided into a shallow layer and a deep layer, which becomes the sternothyoid and thyrohyoid muscles. Although the shallow layer becomes the splenius spread in the cervical region, the intermediate area in humans is degenerated and the splenius is separated into the internal and external muscles. The internal muscle becomes the sternohyoid muscle and runs straight into the anterior cervical region. The lower part of the external muscle grows in the external and inferior direction and becomes the omohyoid, which runs obliquely in the lateral l cervical area ${ }^{14}$. Therefore, anomalies caused by the adhesion of the fetal omohyoid and the cleido-sternohyoideus are from primitive morphology of the splenius ${ }^{15,16,17 .}$

It has been suggested that because the human omohyoid is degenerating, the incidence of anomalies is high. Unusual omohyoid forms described by Bergman et al include: cleidofascialis, which originates from the middle third of the clavicle and inserts in to the fascia colli (neck); Cleidohyoideus, which originates behind the origin of the cleidomastoid part of sternocleidomastoid and inserts onto the body of the hyoid bone; and hyofascialis, which originates from the hyoid and inserts into the omosternoclavicular fascia9.

The occurrence of an accessory muscle in the infrahyoid region may have its implications during diagnostic and surgical procedures. It is essential to know these possible variations because the omohyoid muscle is a reliable landmark in the supraclavicular region. The omohyoid muscle is the best landmark for identifying the internal jugular vein (IJV); thus any variation in this muscle may increase the risk of injuring the IJV during surgeries in the lower neck region ${ }^{18}$. The wide variability of the position of omohyoid muscle is likely to have implications for the surgical management of oral and oropharyngeal cancer ${ }^{19}$.

There are reports of clinical cases due to abnormal omohyoid muscle, contracture of which causes congenital torticollis ${ }^{20,21}$. Hypertrophied omohyoid muscle can cause brachial plexus irritation 22 ; omohyoid syndrome in which swelling appears when the throat ascends and subsides with its descent in unison with omohyoid prominence. The sternomastoid is passively tented up by an abnormal underlying omohyoid. The latter appears to have lost its restriction to bowstring by the retaining deep cervical fascia ${ }^{23}$ and compression 
of the internal jugular vein by the omohyoid muscle, leading to modifications in intra cerebral venous hemodynamic, which can be affected in yawning 24 .

In conclusion, an unusual cleidohyoideus muscle was appeared bilaterally. Variations of the infrahyoid muscles, including the cleidohyoideus accessorius, are important to consider because of their relevance in diagnostic studies and as surgical landmarks. Knowledge of potential muscular variations in the region is important for physicians or head and neck surgeons.

\section{CONFLICT OF INTEREST: None}

\section{REFERENCES:}

1. Le Double AF. Traite des variations du systeme musculaire de I'homme et de Ieur signification au point de vue de l'anthropologie zoologique. Tome II. Paris, Libraire C. Rerinwald, Schleichar Freres. 1897; 129.

2. Tubbs RS, Salter E G, Oakes WJ. Unusual origin of the omohyoid muscle. Clin Anat. 2004; 17:578-82.

3. Miura M, Kato S, Itonaga I, Usuy T. The double omohyoid muscle in humans: Report of one case and review of the literature. Okajima Folia Anat Jpn. 1995;72: 81-9.

4. Rai R, Ranade AV, Nayak SR, Vadgaonkar R, Pai MM, Krishna murthy A. A study of anatomical variability of the omohyoid muscle and its clinical relevance. Clinics. 2008; 63:521-4.

5. Tamega OJ, Garcia PJ, Soares JC, Zorze tto NL. About a case of absence of the superior belly of the omohyoid muscle. Anat Anz. 1983; 154:39- 42.

6. Bolla SR, Nayak S, Vollala VR, Rao M, Rodrigues V. Cleidohyoideus. A case report. Indian Journal for the Practising Doctors. 2007; 3(6):1-2

7. Loth E. Musceln des Halses. Beitrage zur Anthropologie der Negerweichteile. Stutgart, Streker \& Sc hroder. 1912; 58-73.

8. Steinbach K. Über Varietaten der Unterzungenbein und Brustmuskulatur. Anat Anz. 1923; 15: 488-506.

9. Bergman R.A., Thompson S.A., Afifi A.K., Saadeh F.A. Compendium of Human Anatomic Variation. Urban \& Schwarzenberg. Baltimore -Munich 1984; 34

10. Hatipoglu E S., Kervancioglu P, Tuncer M C. An unusual variation of the omohyoid muscle and review of literature. Ann Anat. 2006; 188: 469-472.

11. Stark ME, Wu B, Bluth BE, Wisco JJ. Bilateral accessory cleidohyoid in a human cadaver. Interna tional Journal of Anatomical Variations (IJAV). 2009; 2: 122- 123.

12. Sukekawa R and Itoh I. Anatomical study of the human omohyoid muscle: Regarding intermediate morphologies between normal and anomalous morphologies of the superior belly. Anat Sci Int. 2006; 81:107-14.

13. Anderson RJ. The morphology of the omohyoid muscle. J. Me d. Sci. 1881; 10:1-17.

14. Lewis WH. The development of the muscular system. In: Manual of Human Embryology, 1st edn (Keibel F, Ma ll FP, eds). Lippincott, Philadelphia, 1910; p.454522.

15. Takano T, Takaya M, lizuka K. A statistical study of abnormal muscle of infrahyoid. IwateidaI Kaibou Gyouseki. 1955; 2:113- 24.

16. Sato Y, Oota Y, Yokota A La anomalio de M. omohyoideus ce Japanoj. Nichidai Igaku Z. 1969; 28:431-44. 
17. Buntine JA. The omohyoid muscle and fascia. Aust NZ Surg. 1970; 40:86-8.

18. Kasapoglu F, Dokuzlar U. An Unknown variation of Omohyoid Muscle. Clin Anat 2007; 20:964- 65.

19. Mizen KD, Mitchell DA. Anatomical variability of omohyoid and its relevance in oropharyngeal cancer. Br J Oral Maxillofac Surg. 2005 Aug; 43(4):285-8.

20. Pirsig W. Congenital torticollis with dislocation of the larynx and trachea caused by contracture of one omohyoides muscle. Arch Otorhinolaryngol. 1977 May 31; 215 (3-4):335- 7.

21. Shih TY, Chuang JH. Fibrosis of the omohyoid muscle-an unusual cause of torticollis. J Pediatr Surg. 1998 May; 33(5):741-2.

22. Fiske LG. Brachial plexus irritation due to hypertrophied omohyoid muscle; a case report. J Am Med Assoc. 1952 Jun 21; 149(8):758- 9.

23. Wong DS, Li JH. The omohyoid sling syndrome. Am J Otolaryngol. 2000 SepOct;21(5):318-22

24. Patra P, Gunness TK, Robert R, Rogez JM, Heloury Y, LeHur PA, Leborgne J, Laude M, Barbin JY. Physiologic variations of the internal jugular vein surface, role of the omohyoid muscle, a preliminary echographic study. Surg Radiol Anat. 1988; 10(2):107-12.

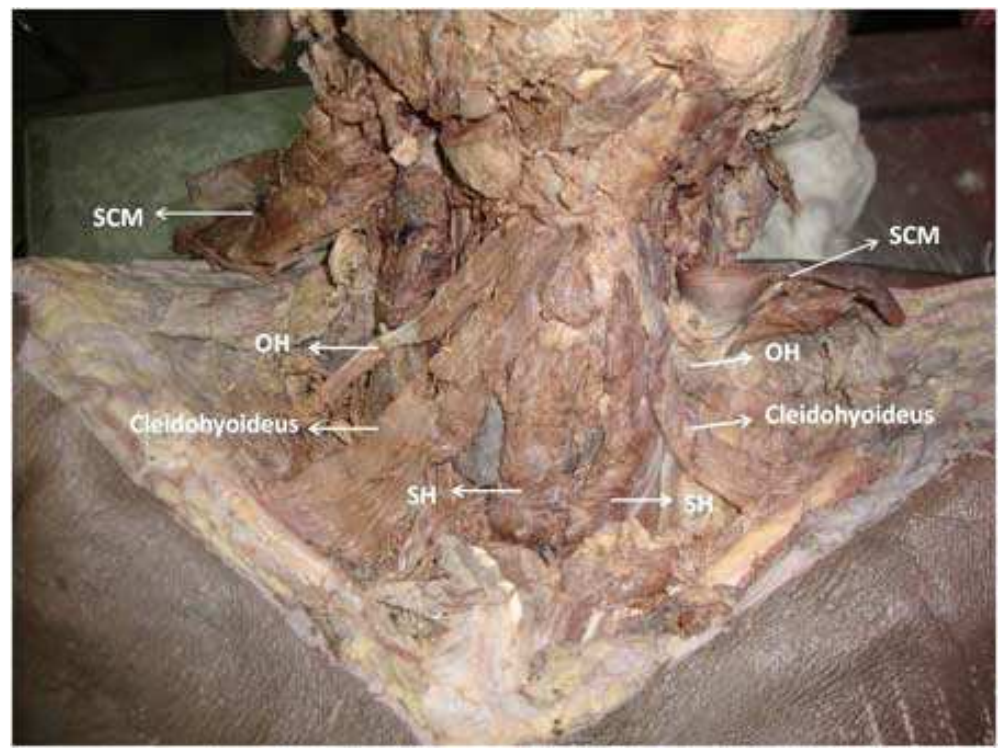

Fig.1 - Cleidohyoideus accessorius (ca) of both sides after Sternocleidomastoids (scm) cut away from clavicle. Sternohyoid (sh) and Omohyoid (oh) seen. 